\title{
ESTADO DE LAS ERMITAS PERTENECIENTES A LA JURISDICCIÓN DE CHIPUDE (LA GOMERA) EN EL ÚLTIMO CUARTO DEL SIGLO XVII
}

\author{
Pablo Jerez Sabater*
}

\section{RESUMEN}

A través del análisis de las visitas pastorales de la parroquia de Chipude conservadas en el Archivo Tarquis de la Biblioteca General de la Universidad de La Laguna, estudiamos el estado de las ermitas dependientes de esta jurisdicción en el último cuarto del siglo XVII. De las cuatro que existían durante la Época Moderna, tan solo dos han sobrevivido hasta nuestros días, de ahí el interés en rescatar la memoria histórica de las desaparecidas ermitas de San Andrés y Santa Catalina.

Palabras clave: ermitas, La Gomera, Chipude, patrimonio artístico.

\section{STATE OF THE HERMITAGES PERTAINING TO THE JURISDICTION \\ OF CHIPUDE (LA GOMERA) IN THE LAST QUARTER \\ OF THE XVII ${ }^{\mathrm{TH}}$ CENTURY}

\section{Abstract}

Through analysis of the pastoral visits of the parish of Chipude conserved in the Archivo Tarquis of the General Library of the University of La Laguna, we studied the state of the dependent hermitages of this jurisdiction quarter of the XVII ${ }^{\text {th }}$ century. Of the four which they existed during the Modern Time, only two have survived to the present time, of there the interest in rescuing the historical memory of the missing hermitages of San Andrés and Santa Catalina.

KeYwords: hermitages, La Gomera, Chipude, art heritage. 


\section{INTRODUCCIÓN}

Hace ya más de una década que comenzamos la labor de estudiar un tema que consideramos que estaba aún por hacer, esto es, el estudio de las ermitas en la isla de La Gomera durante la Época Moderna.

Salvando algunos ejemplos puntuales, como las ermitas de San Sebastián, del profesor Darias Príncipe ${ }^{1}$, o las históricas de Vallehermoso ${ }^{2}$, la historiografía no ha sido prolija en estudios -aunque sí en cuanto a referencias tangenciales-respecto a esta cuestión. Estas construcciones, en su mayoría de pequeñas dimensiones y de patrimonio artístico de escaso valor, cumplieron en su momento un papel crucial en la isla, ya que la dispersión de la población y el numeroso conjunto de aldeas existentes hacían de las ermitas verdaderas pregoneras del hecho religioso.

No hemos de olvidar que la intrincada orografía de La Gomera fue también un elemento propicio para la construcción de este tipo de fábricas a lo largo de la isla, si bien, en ocasiones, la dificultad de su acceso, así como el propio abandono de las tierras de cultivo y la dispersión del campesinado hacia otro tipo de labranzas -baste recordar el auge del plátano o el tomate en la comarca norte-, hizo que estas cayeran en el olvido durante largo espacio de tiempo y otras, desgraciadamente, quedaran relegadas al abandono y posterior ruina.

Partiendo de estas premisas generales, también hemos de señalar que no todas las ermitas corrieron la misma suerte. Aquellas cuyo patronato estaba vinculado a la familia condal, como las de San Juan en Benchijigua o la de los Remedios, en San Sebastián, tuvieron fortuna histórica durante la Edad Moderna, no faltándoles remiendo arquitectónico en su fábrica cuando amenazaban ruina o el visitador de oficio disponía en sus mandatos el adecentamiento de las mismas, aunque las primeras décadas del siglo xx trajeran consigo su destrucción y olvido.

En ocasiones, aquellas ermitas patrocinadas por las élites tampoco sufrieron el paso del tiempo y la desidia humana con la misma crudeza. La de San José en Tejiade ${ }^{3}$ puede ser una buena muestra. Sin embargo, este vasto conjunto de construcciones dispersas tuvo su verdadero momento de esplendor durante el siglo XVII, contabilizándose en La Gomera más de veinte ermitas a lo largo de su geografía, y su ocaso durante el difícil Ochocientos, etapa de crisis económica y demográfica en la isla.

En esta complicada coyuntura, analizamos, a través de las visitas pastorales, el caso de cuatro ermitas vinculadas a la jurisdicción pastoral de la parroquia de

* Escuela de Arte Pancho Lasso, Lanzarote. Email: pablojerezsabater@gmail.com.

1 Darias Príncipe, Alberto: Lugares colombinos de la Villa de San Sebastián de La Gomera, Cabildo Insular de La Gomera, 1986.

2 Fernández Fernández, Blanca: Vallehermoso, sus ermitas: religiosidad popular, Cabildo de La Gomera, 1999.

3 Jerez Sabater, Pablo: «Memoria histórico-artística de la ermita de San José en Tejiade, La Gomera", en Estudios Canarios, Anuario del Instituto de Estudios Canarios, n. ${ }^{\circ}$ LIV, San Cristóbal de La Laguna, 2010. 
Nuestra Señora de La Candelaria en Chipude, durante el siglo xvir: Santa Catalina, San Nicolás de Tolentino, la Adoración de los Santos Reyes y San Andrés.

\section{EL ESTADO DE LAS ERMITAS DEPENDIENTES DE CHIPUDE DURANTE EL SIGLO XVII}

Antes de centrarnos en el asunto que nos ocupa, señalemos rápidamente el caso de Chipude y su parroquia durante este periodo. El curato es fundado en 1642, tras el traslado de la iglesia hasta su emplazamiento actual, habiendo existido con anterioridad una ermita en el lugar conocido como Candelaria la Vieja, más cercano a la Fortaleza ${ }^{4}$. Esta circunstancia es fundamental para entender cómo Chipude rápidamente será el eje en torno al cual se produzca la centralización de la jurisdicción de una serie de ermitas bastante dispersas de este núcleo poblacional. En efecto, si la distancia hasta este pago era enorme respecto a la capital, mucho más lo eran las de aquellas ermitas fundadas y emplazadas en este sector de la isla, cuya posibilidad real de recibir asistencia religiosa dependía casi en exclusiva del curato de Chipude. Siguiendo el trabajo anteriormente citado, la ermita es elevada a la categoría de parroquia en 1655 gracias a la intervención de don Diego de Herrera Cascante (personaje que veremos vinculado a la ermita de Santa Catalina) y del alférez don Enrique de Mora Melián, estante en Hermigua y patrono del convento dominico de la localidad, así como mayordomo de fábrica de la parroquia de Nuestra Señora de la Encarnación del mismo valle 5 .

Una vez apuntada la creación del curato y su elevación a parroquia, su jurisdicción era realmente amplia, pues abarcaba no solo los pagos de Chipude, sino que llegaba incluso a la aldea de Arure, donde se encontraba la ermita de San Nicolás y la más recóndita de la Adoración de los Santos Reyes, en Valle Gran Rey. La dispersión y lo tortuoso de los caminos para acceder a estas construcciones fue una de las constantes señaladas por los visitadores, quienes llegaban incluso a no visitarlas por lo azaroso y peligroso del trayecto.

De las cuatro ermitas dependientes de Chipude durante este siglo XVII, tan solo dos sobreviven en la actualidad: San Nicolás de Tolentino (muy transformada) y la Adoración de los Santos Reyes. Para los casos de Santa Catalina y San Andrés, la fortuna histórica no ha sido tan benévola, tanto así que ni la memoria oral las recuerda, quedando como testigos de su existencia la documentación generada por las visitas pastorales conservadas de la parroquia de La Candelaria y una pequeña talla del apóstol en el nicho central del segundo cuerpo del retablo mayor de la iglesia chipudana.

${ }^{4}$ Díaz Padilla, Gloria y Rodríguez Yanes, José Miguel: El señorio de las Canarias occidentales. La Gomera y El Hierro hasta 1700, Cabildo de La Gomera y Cabildo de El Hierro, 1990, p. 543.

5 Jerez Sabater, Pablo: «Estudio del patrimonio histórico-artístico de Hermigua», en Hermigua en el tiempo, Ilustre Ayuntamiento de Hermigua, 2010, p. 32. 


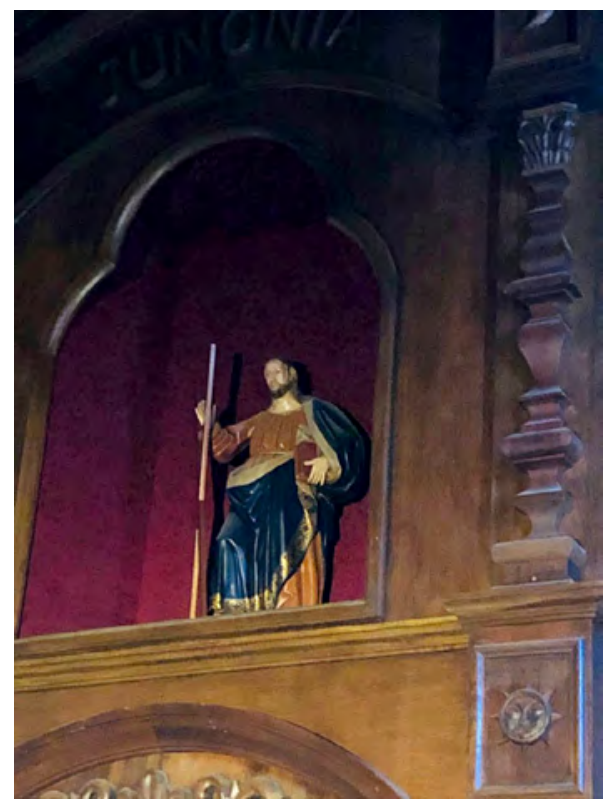

Fig. 1. San Andrés, anónimo siglo Xvir. Iglesia de la Candelaria, Chipude, La Gomera.

En este sentido, se trata de una talla bastante tosca que podría fecharse en el siglo XVII y que estilísticamente continúa los patrones populares de otras imágenes contemporáneas en la isla como el San Juan Bautista de Agulo, piezas algunas que han sido tratadas por nosotros en un artículo de hace algunos años ${ }^{6}$.

Por otro lado, la historiografía de las ermitas existentes nos remite, tan solo, a un señero y puntual trabajo de Alberto Darias Príncipe, La Gomera: espacio, tiempo y forma, donde en su capítulo cuarto reseña la información histórica de ambas construcciones. Estamos, por tanto, ante una investigación difícil de acometer por la escasa documentación que conservamos y por la desaparición de dos de estas ermitas, de ahí que planteemos este artículo como una primera aproximación al asunto, a fin de completar esta investigación si hubiera posibilidad de acceder a nuevo material documental.

El periodo analizado de las visitas pastorales lo hemos circunscrito al último tercio del siglo XVII (1675-1701) porque es aquel del que conservamos documentación relativa a las mismas. Aun sin ser un periodo suficientemente amplio y del que

6 Jerez Sabater, P: «Nuevos aportes al estudio de la escultura barroca en La Gomera», en Actas del XXI Coloquio de Historia Canario Americana, Casa de Colón, Las Palmas de Gran Canaria, 2014, pp. 38-44. 
no podamos extrapolar datos para generalizar, creemos que son lo suficientemente esclarecedores como para hacernos una idea de su estado en la centuria siguiente, no pudiendo aseverar estas cuestiones ante la falta de los fondos relativas a dichas fábricas.

De San Nicolás de Tolentino, en la aldea de Arure, ha sido apuntada como fecha de fundación las postrimerías de la década de $1510^{7}$ y debió ser en sus orígenes una ermita no muy diferente del resto de estas fábricas en la isla: pequeñas dimensiones, portada de cantería de medio punto, separación de la capilla y entrada en uno de sus flancos laterales. Idéntica situación debió existir para la de la Adoración de los Santos Reyes, siendo fundada también en los albores del siglo xvi al amparo, quizá, del ingenio azucarero instalado en este valle durante este siglo. Su situación en una de las laderas de este sinuoso y profundo barranco fue quizá su salvación durante la Edad Moderna, así como el empeño de sus pocos vecinos en su adecentamiento; pensemos solamente en la siguiente nota para hacernos una idea de su situación:

Hay aquí una ermita para la banda de Chipude con la advocación de la Virgen de los reyes y está muy decente y muy pobre y junto a esta ermita y alrededor de ella están tres casitas una de tejas y dos pajizas 8 .

Queda probada la pobreza de la ermita y del lugar. Respecto a las otras dos ermitas, Santa Catalina y San Andrés, tan solo conocemos un dato y de nuevo la referencia la tenemos a través del manuscrito anónimo del siglo XVIII:

Llámase esta loma [Iguala] San Andrés porque había allí una ermita del santo la que mandó desbaratar D. Miguel Camacho en el tiempo de su visita y el que el Santo se trajera a la iglesia en donde se halla de presente por la indecente que estaba, es tradición que esta ermita estaba situada en la mediodía alta como es en Vega de Contreras, Bachiller, etc y los antiguos viendo que no llovía para abajo quitaban al santo de la ermita y lo llevaban a un charco que llaman texo, lo amarraban con una soga y lo echaban a nadar en un charco, entre estos que fueron dijo uno que lo sacaran, que él salía por fiador y que mudaran la ermita al paraje y ha dicho, así se ejecutó y después se ha conservado lloviendo hasta la mar, estas son noticias pero no ha ningún documento ${ }^{10}$.

Aparte de la curiosidad de la noticia, que habría que relacionarla, desde nuestro punto de vista, con algunas tradiciones de carácter aborigen como la búsqueda de lluvia a través de la ofrenda, lo verdaderamente importante es la noticia

7 Darias Príncipe, Alberto: La Gomera. Espacio, tiempo y forma, Fred Olsen, 1992, p. 307.

8 Anónimo, Ms. Siglo xviII: Descripción de la Ysla de La Gomera, Manuscrito del siglo XVIII, Fondo Millares Torres, vol. v. Archivo del Museo Canario, Las Palmas de Gran Canaria, fol. 13r. Existe una versión transcrita del manuscrito, pero hemos consultado el original.

${ }^{9}$ Miguel Camacho era abogado de los Reales Concejos, fiscal general del Obispado y visitador de La Gomera y El Hierro en 1766.

${ }^{10}$ Anónimo: Ms. Siglo XviII., fol. 15v. 
del emplazamiento y, como puede entreverse, la desaparición de la ermita ya en este siglo XVIII. Por tanto, una construcción de corta vida.

Ahora bien, ¿`cómo enfrentarnos a su análisis durante este periodo final del siglo XVII? Pues, a falta de mayor documentación, a través de las visitas pastorales, fuente constante de noticias para nuestros trabajos, puesto que la documentación relativa a las mismas, en numerosas ocasiones, ha desaparecido. $Y$, aunque su información no sea completa ni siquiera comparable a la que proporcionaría su libro de fábrica, al menos obtenemos algunas fechas y nombres para situarla en el contexto de la historia de la religiosidad en la isla de La Gomera.

La primera visita conservada en la documentación de la parroquia de Chipude data de 1675 y tiene como protagonista al obispo Bartolomé García Ximénez, quien visita estas tierras y anota lo siguiente:

Ay en el distrito desta Parrochia quatro hermitas. Una de Santa Catalina en que aun no se celebra hasta que el capitán Diego de Herrera Cascante que la a reedificado la acave de perficionar y cumpla lo que tiene ofrecido en la lizencia que para reedificarla se le dio, aunque fue con cláusula de que no avia de dar quentas a los visitadores y no tenemos por conveniente se den semejantes licencias en esta forma y mas que sobran hermitas en la ysla.

Hermita de los Reyes en Valle Gran Rey. Cuida de ella Gaspar de Marichal, tampoco no tiene libro ni de quentas. Mandósele se le haga, y que pida limosna ${ }^{11}$.

Dos conclusiones principales podemos extraer de estas breves noticias. La primera tiene relación con el capitán Diego de Herrera, de quien ya habíamos señalado su implicación en la elevación al rango de parroquia de la Candelaria de Chipude, y, por otro lado, el comentario que hace acerca del excesivo número de ermitas en la isla. Y es que, como señalamos en la introducción, la elevada cantidad de estas construcciones respondía a la dispersión de los caseríos y aldeas, pero también algunas a la importancia de familias que en sus tierras decidían, por iniciativa propia, erigir una ermita dedicada a un santo de especial devoción y significación para ellas. Tal es el caso de Santa Catalina, de la que no hemos podido rastrear mayores noticias que las que ofrecemos en este trabajo, pues no conservamos siquiera ni el lugar donde pudo haber estado situada, aunque el topónimo existe en una loma cercana a La Dama, de ahí que apuntemos este punto como su posible ubicación durante esta centuria. De hecho, visitado el lugar encontramos un pequeño núcleo de seis casas prácticamente deshabitado pero en el que se conserva un nicho moderno vacío. No descartamos la posibilidad de que algún vecino conserve una talla en su domicilio, aunque ni los lugareños consultados confirman la advocación de la misma ni si existió una ermita en el lugar.

${ }^{11}$ Biblioteca General de la Universidad de La Laguna, Archivo Miguel Tarquis, carpeta 11, fol. $112 \mathrm{r}$. 


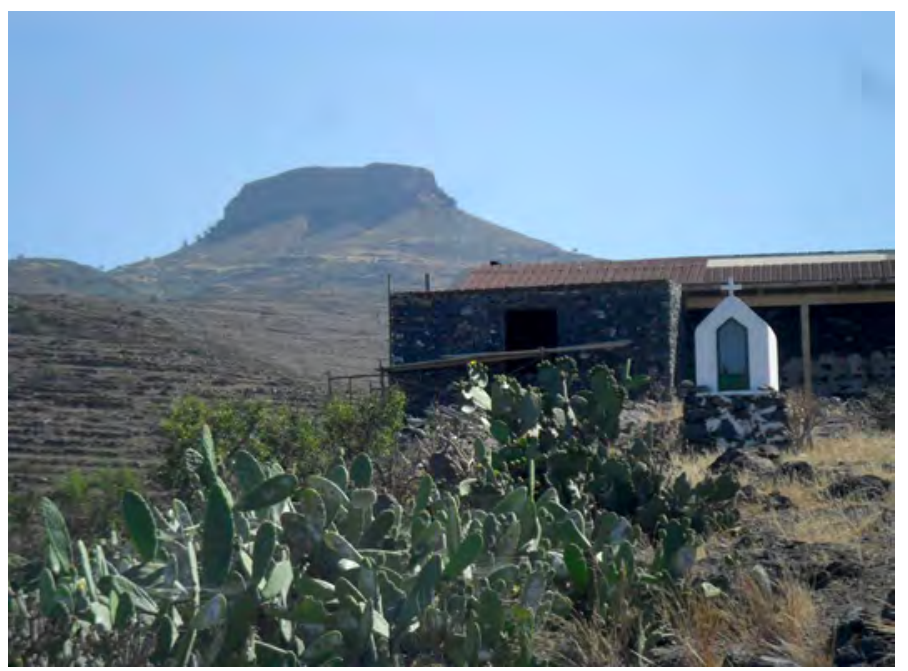

Fig. 2. Nicho vacío en el lugar de Santa Catalina, municipio de Vallehermoso, La Gomera.

Entre los ańos 1675 y 1680 contamos con dos nuevas visitas a estas ermitas, pero la documentación -casi ilegible- no revela noticias ni de la fecha exacta ni de los visitadores. Sin embargo, aportan nuevas noticias sobre el conjunto, en especial sobre la de San Nicolás en Arure, sin lugar a dudas la más rica -en cuanto a su feligresía- del conjunto de las ermitas que estaban bajo la jurisdicción de Chipude.

Hermita de San Andrés de que es Mayordomo Luys Delgado, vezino de Valle Hermoso que en la presente visita se hallaba enfermo. Remitió su libro de quentas por mano del vicario de la ysla, y por venir mal formado el borrador por donde se avian de tomar referendamos para la visita venidera el que de sus quentas y lo notamos al fin del libro de nuestra letra=

Hermita de San Nicolás de Tolentino en la Aldea de Arure, de que es Mayordomo Asensio García que dio sus quentas y fue religido por Mayordomo. Falta el borrador del ajuste desta hermita, y se estará a lo que quedó escrito en su libro de quentas ${ }^{12}$.

En esta visita aparecen por primera vez los nombres de dos de las personas que ostentaban la mayordomía de las ermitas: Luis Delgado y Asensio García. Para el caso de la primera hemos de señalar que se trataba de un vecino de Vallehermoso y estos pagos pertenecen, en la actualidad, al mismo término municipal, conservando la toponimia en Iguala en la denominada «Punta de San Andrés», lugar hoy de difí-

12 Ibidem, fol. $122 \mathrm{v}$. 
cil acceso, pero desde el que se divisa una planicie cerealista enmarcada entre barracos, siendo con toda probabilidad el lugar donde estuvo esta ermita hasta su desaparición en el siglo xviII. Además, ambas revelan la existencia de libros de cuentas que no nos han llegado hasta la actualidad o, al menos, no hemos podido localizarlos para hacernos una idea de su patrimonio en estos momentos, pero remitimos a la idea de pobreza y austeridad formal en cuanto a su tipología, quizá conservando apenas un pequeño nicho empotrado en la capilla donde estaría alojado el santo titular de la ermita.

La segunda relación es más interesante respecto a las noticias que ofrece:

Hallose el borrador de las quentas desta hermita [San Nicolás de Tolentino] como Mayordomo a Asensio García. Dio sus quentas por ante fray Matheo de la Rosa, cura del dicho lugar de Chipude en 30 de septiembre de 75, desde el tiempo [...] de Agosto de 73 hasta Agosto de 75 tubo de cargo 165 reales y los quentos de descarga de 97, conque fue alcanzado el dicho Mayordomo. [...] Diosele lizencia para traer el santo de Garachico y se le encargó el cuidado de cobrar ${ }^{13}$.

La importancia de Garachico como punto de adquisición de imágenes devocionales es sobradamente conocido desde la implantación del andaluz Martín de Andújar y la apertura de su taller en este boyante puerto comercial. Por una cuestión de fechas, este encargo - del que no sabemos si llegó a efectuarse-pudo haberse contratado con cualquiera de los dos principales escultores del momento estantes en la villa: Blas García Ravelo (1618-1680) o Francisco Alonso de la Raya (16191690). Lo que nos interesa, al no conservar la pieza escultórica, es el interés de la licencia para efectuar la compra del santo en este puerto, revelando la importancia de los talleres estantes en Garachico como el principal foco artístico del momento, amén de ser el desembarcadero habitual para los vecinos de la isla de La Gomera.

$\mathrm{Y}$ es que en estos momentos la documentación no hace referencia a maestros de origen local que pudieran abastecer a estas ermitas y otras obras religiosas de esculturas o pinturas. Tenemos que esperar hasta mediados del siglo XVIII para encontrar al primer artista local documentado, el conocido como Luis, el pintor de Agulo, tal y como se desprende de un testamento otorgado por D. Antonio de la Cámara y Ávila en 1752 y de su encargo de una imagen de san Vicente Ferrer para el convento de San Pedro Apóstol de Hermigua. Por tanto, este revelador dato acerca de la compra de imágenes a los talleres de Garachico desde La Gomera nos parece importante, ya que no son numerosas las esculturas que nos han llegado hasta la actualidad de esta centuria, siendo en su mayoría piezas de importación andaluzas e incluso americanas.

En el año 1680 se realizó una nueva visita a este conjunto de ermitas, siendo una de las más completas registradas en el libro de fábrica disponible de Chipude. $\mathrm{Al}$ igual que en el caso anterior, el estado ilegible del documento nos ha imposibili-

${ }^{13}$ Ibidem, fol. 113r. 
tado saber quién actuaba como visitador pero, al menos, hemos conseguido transcribir la mayor parte de la misma:

Visita de Hermitas=

Visitosse en relación la hermita de Santa Catalina, entendiosse está la puerta abierta y con indecensia, mándese serrar la puerta y para ello se dio comisión y mandato a Luis Delgado de la Paz para que le pusiese una tabla con cuatro clavos y que notificasse a Diego de Herrera la tubiesse decente y reparada y no permitiesse abrirse hasta estar la puerta con la decensia debida, este hombre tiene más de 100 ańos y está impedido y no se pudo traer por referencia del visitador.

Hermita de San Nicolás [Al margen]. Visitosse la Hermita de San Nicolás y se halló por mayordomo a Asensio García y se le hizo el cargo que fue de novecientos setenta y siete y seis quartos y de descargo confie [...] quarenta y siete Reales y fue alcanzada la dicha hermita en quarenta y nueve Reales y dos quartos y el dicho mayordomo dio gracias y fue religido en dicha mayordomía.

Hermita de San Andrés [Al margen]. Visitosse dicha hermita y se halló por mayordomo a Luis Delgado y se le hisso el cargo que fue de 176 Reales, descargosse con siento setenta. Dijo gracias el dicho. Fue nombrado por nuebo mayordomo Pedro Truxillo.

[Al margen]. Visitosse la hermita de los Reyes y se halló por mayordomo a Garpar Marichal, cargo de quinientos y cinco Reales, descargosse en siento setenta y cinco Reales. Dio gracias y fue religido ${ }^{14}$.

El estado de pobreza de las mismas es un hecho constatable, como es el caso de Santa Catalina, donde refiere que la indecencia llegaba a tal extremo que ni puerta tenía. Este tipo de situaciones, por desgracia, venía a ser una tónica general en la mayoría de las ermitas del momento, aunque sorprende en este caso la desidia por parte del capitán Diego de Herrera en su adecentamiento, porque si bien podríamos entender el abandono por falta de recursos y limosnas en ermitas de menor rango, en este caso, siendo de fundación privada, es menos comprensible aún. Desgraciadamente, no tenemos siquiera un solo dato que nos ayude a situarla en la geografía insular -salvo la hipótesis que hemos planteado en cuanto a la toponima-, quedándonos, por tanto, huérfanos en el conocimiento de una construcción religiosa que tuvo que ser de relativa importancia para ser anotada en este tipo de visitas pastorales. Otro dato interesante nos parece el descargo de 170 reales para la ermita de San Andrés, una cantidad nada desdeñable que podría responder a una reparación o, incluso, una reedificación de la misma, así como el cargo de 505 reales de la Adoración de los Santos Reyes de Valle Gran Rey, una considerable suma de dinero implementada gracias a las limosnas de la pequeña población estante en los pagos

${ }^{14}$ Ibidem, fol. 199r. 


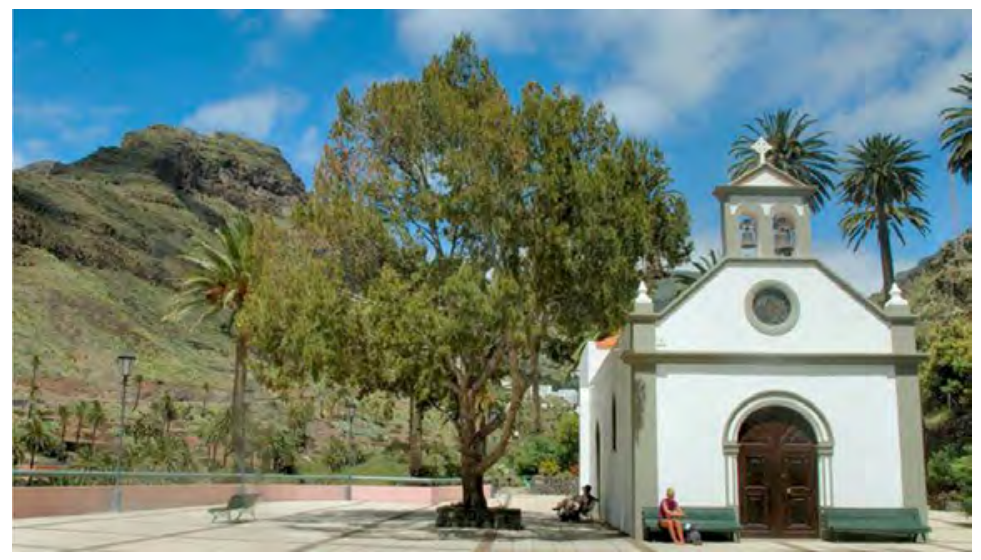

Fig. 3. Estado actual de la ermita de los Santos Reyes, en Valle Gran Rey, La Gomera.

del barranco, alejada del principal núcleo de Arure, de quien dependía con seguridad para el desplazamiento del cura como oficiante de las misas.

La última visita pastoral registrada de esta centuria corresponde al año de 1690 y en ella aporta interesantes datos como la distancia de las ermitas respecto a la parroquia de La Candelaria de Chipude:

Visitosse la hermita de San Nicolás de Tolentino que está en el lugar de Arure, distrito desta parrochia en donde se dice missa todos los días de fiesta diciendo el cura dos missas y se halló con en dicha hermita un missal muy indisente de calidad y que [...] [//fol. 123r] no se dixesse missa hasta tanto que los vezinos que ay [...] Está de distancia de la parrochia una legua. Hallose por mayordomo a Asensio García y se le alcanzó en siento y ochenta y un Reales y seis quartos. El cargo impuesto de 391 y 6 quartos y el descargo de 208. Dixo le escusasen y se nombró por mayordomo a Domingo Hernandez Bruma, alcalde de la dicha aldea y se le entregaron las alajas que constan del inventario que está en el libro.

Visitosse la hermita del Señor San Andrés que está distante de la Parrochia tres quartas de legua. Hallose por mayordomo a Pedro Truxillo Bencomo el qual dio por estar achacoso en el Valle de Hermigua. El Venerable cura de la dicha parrochia impuso un cargo de 100 Reales y el descargo de 110 conque fue alcanzada la hermita en 10 Reales y por estar en dicho lugar inhaceso se nombró por mayordomo al alférez Francisco de Lima. Está la dicha hermita con toda desencia entregándosele las alajas que constan de inventario que está en el libro. Mandose reparar un pedazo de pared.

Visitosse la hermita de Santa Catharina Martyr y no se tomó quenta porque la tienen dizada los herederos del capitán Diego de Herrera que tienen el cuidado de asearla y que lo está. No piden limosnas. Es a manera de oratorio y le hacen fiesta su día. Está distante de la parrochia una legua. 
Visitosse la hermita de los Santos Reyes. Hallose por mayordomo a Gaspar Marichal y por estar enfermo en su nombre Pascual de Niebla su cuñado importó el cargo 25 Reales y el descargo 56 Reales fue alcanzada la dicha hermita en 34 Reales. Y porque se reconoció la tibiesa en pedir las limosnas se nombró por mayordomo al dicho Pascual de Niebla. Está con todo aseo y se entregó las alajas que constan de inventario y se mandó hazer por el venerable cura. Está distante de la parrochia más de legua y muy áspero el camino con $\operatorname{riscos}^{15}$.

Sin duda, estamos ante la descripción más importante de cuantas hemos seńalado. No solo la distancia, perfectamente marcada en leguas respecto a la parroquia, sino también aquellos datos referentes a mayordomías, cuentas de carga y descarga y estado de aseo de las mismas.

Ya hemos señalado a lo largo del artículo que, en cuanto a importancia, por población y feligresía $-19 \%$ en el censo de $1680^{16}$-, la ermita de San Nicolás de Tolentino en Arure constituía el núcleo referencial de la comarca dependiente de la jurisdicción de Chipude. Los datos referentes a las misas que allí se ofrecían, así como las importantes sumas de reales en cuanto a cargas y descargas, así lo atestiguan. En el siglo XVIII la situación no cambió demasiado, siendo las misas oficiadas cada quince días ${ }^{17}$.

Por su desconocimiento, la ermita de Santa Catalina Mártir tiene un mayor interés para nosotros. Aun sin saber, como hemos señalado, su ubicación, al menos esta visita nos señala que «es a manera de oratorio», por lo que tampoco sería descartable que se tratara de un pequeño nicho en los pagos donde dicen Santa Catalina, en una lomada cerca de La Dama, al sur de Chipude, hoy despoblado prácticamente en su totalidad, como hemos advertido al comienzo de este trabajo, y donde en la actualidad existe un pequeño nicho, aunque de factura reciente.

Respecto a la ermita de la Adoración de los Santos Reyes, nuevamente nos encontramos ante el comentario que hace referencia a lo tortuoso del trayecto, al que se refiere como "áspero el camino con riscos». Y es que la pequeña ermita, hasta bien entrado el siglo XIX, no contó con la importancia que hoy tiene, debido sobre todo al aumento demográfico de la zona de Valle Gran Rey. Sea como fuere, al menos ha sabido conservar su espíritu y, sobre todo, la pequeña pintura de factura popular que representa la Adoración, realizada, quizá, en la segunda mitad del siglo XVIII.

\section{CONCLUSIONES}

A pesar de no contar con numerosa documentación sobre estas ermitas y conservarse en pie en la actualidad solo dos, creemos que el interés de las mismas es notable para el conocimiento del patrimonio religioso de la isla de La Gomera.

15 Ibidem, fols. 122r-123v.

16 Darias Príncipe, A: op. cit., p. 302.

17 Anónimo: Ms. Siglo xviri, fol. 9v. 
En los últimos años el estudio de este tipo de construcciones ha ganado un creciente interés, apostando por una visión en conjunto que englobe el panorama insular durante la Edad Moderna.

Si bien es cierto que partir de las visitas pastorales puede ofrecernos solo una visión parcial del asunto, ante la falta de documentación y de los libros de fábrica de las mismas se torna reveladora pues, al menos, nos permite situar en el espacio y en el tiempo estas ermitas y sus mayordomos, sus dependencias y conexiones, sus rentas económicas y los datos más relevantes sobre su estado durante esta centuria.

Hoy la memoria ha olvidado las de San Andrés y Santa Catalina, pero no por ello podemos cejar en nuestro empeño de devolver, en la medida de nuestras posibilidades, la importancia manifiesta que tuvieron estas ermitas en la isla de $\mathrm{La}$ Gomera entre los siglos XVI y XVIII, verdaderos motores sociales y religiosos del interior de esta isla y que conciernen a las aldeas y a los núcleos más desperdigados de su impresionante orografía. 